\title{
Definiciones y aproximaciones teóricas al género de la literatura de viajes*
}

Fecha de recepción: 22 de agosto de 2015

Fecha de aprobación: 08 de marzo de 2016

\section{Resumen}

Este artículo de reflexión pretende hacer un recorrido teórico por el género de la literatura de viajes; exponer sus diferentes enfoques tanto históricos como socioculturales, y las diferentes formas de acercamiento al género desde la teoría crítica literaria. De igual modo, este artículo se pregunta por la importancia del género en la literatura latinoamericana, como ha sido su evolución histórica y su aporte a la construcción de la memoria y la identidad del continente.

Palabras clave: literatura de viajes, Latinoamérica, memoria, historia, identidad, crítica literaria.

Citar: González Otero, A. (julio-diciembre de 2016). Definiciones y aproximaciones teóricas al género de la literatura de viajes. La Palabra, (29), 65-78. doi: http:// dx.doi.org/10.19053/01218530.n29.2016.5701

\section{Angélica González Otero}

Actualmente, ejerce como docente de tiempo completo e investigadora de la Licenciatura en Lingüística y Literatura, Universidad La Gran Colombia (Bogotá). angelica.gonzalez@ ugc.edu.co

* Este artículo de reflexión es parte de la investigación realizada para obtener el título de Magíster en Literatura en la Pontificia Universidad Javeriana. 


\section{la palabra}

\section{Definitions and Theoretical Approximations to the Travel Literature Genre}

\section{Abstract}

This reflection article makes a theoretical journey through the genre of travel literature; in order to present its different historical and sociocultural perspectives, as well as different ways of reading this genre from critical literary theory. Similarly, this article inquires into the importance of the genre in Latin American literature, its historical evolution and its contribution to the construction of memory and identity in the continent.

Keywords: travel literature, Latin America, memory, history, identity, literary criticism.

\section{Définitions et approches théoriques au genre de littérature de voyage}

\section{Résumé}

Cet article réalise un parcours théorique de la littérature de voyages. On expose diverses approches historiques, socioculturelles et de la théorie littéraire sur ce genre. On se demande quelle a été l'importance de ce genre dans la littérature latino-américaine, quelle a été son évolution historique et sa contribution à la mémoire et à la construction de l'identité du continent.

Mots-clés : littérature de voyage, Amérique Latine, mémoire, histoire, identité, critique littéraire. 
Hablar pues de literatura de viajes, o de viaje y literatura, es hablar de un género o subgénero, según la simpatía o generosidad del clasificador, pero también hablar de la médula misma del acto narrativo. Por un lado, viajar lleva inexorablemente a tener algo qué contar; y por otra parte, al contar una historia jamás puede prescindirse del recorrido que uno ha hecho, por la vida y por el mundo.

Lorenzo Silva

El acto de escribir sobre los viajes está presente desde los inicios de la civilización occidental: desde los viajes épicos de Jasón, Ulises y los fenicios por el mediterráneo, hasta la llegada de los españoles al continente americano, a finales del siglo XVI, catalogada por algunos como la última hazaña del hombre explorando el mundo. Todos estos acontecimientos viajeros pueden rastrearse en narraciones, crónicas, poemas épicos y en toda suerte de formas de escritura usadas por el hombre para comunicarse.

Este artículo de reflexión pretende exponer algunos aspectos relevantes del género de la literatura de viaje y cómo este ha sido abordado desde distintas perspectivas teóricas y críticas; se pregunta por metodologías usadas para acercarse a los relatos de viaje y por qué el asunto del viaje ha estado relacionado con las hegemonías culturales. De igual modo, se hará un corto recorrido de la historia del género en Latinoamérica; con el fin de dilucidar cómo este ha tenido una enorme incidencia en la construcción de la historia latinoamericana y en la representación que hemos elaborado de nuestra identidad. Dichas representaciones se observan enmarcadas de numerosos prejuicios y estereotipos culturales que han atravesado sutilmente nuestros imaginarios como latinoamericanos. A la par de esto, se intentará rescatar la importancia que ha tenido el género de la literatura de viajes en visibilizar, sobre todo con la llegada del siglo XX, los innumerables contornos narrativos que nos definen latinoamericanos y que intentan establecer una memoria propia que nos otorgue visibilidad e independencia para con el resto del mundo.

Acerca del viaje: concepciones y significados

El viaje como acción humana es un símbolo vinculado de manera intrínseca a la cultura y la vida de los hombres. Por esto, hablar de viaje es tan común como hablar de muerte, de dinero, de comida. Sin embargo, las características y los rasgos del viaje han ido a la par de los cambios históricos, adaptándose a las necesidades de cada época, participando de las búsquedas de los hombres. Viajar para conseguir recursos y hacer intercambios comerciales, viajar para explorar y conquistar territorios, viajar para hacer una peregrinación a un lugar sagrado, viajar para clasificar el mundo natural, viajar para poseer cultura y conocimiento, viajar para obtener gozo y placer. En fin, estas serían cualidades afortunadas del viaje, desplazarse para obtener algo que gratifique la vida individual o colectiva. Pero, al lado de tantas visiones favorables del viaje, encontramos su lado desafortunado, donde el viaje puede no ser el símbolo de la libertad y la independencia, sino todo lo contrario, una expresión de desarraigo y exilio, donde la ruta se vuelve irremediable: refugiados, desplazados, inmigrantes y exiliados de todo el mundo pueden dar fe de esto.

En esta línea de sentido, el viaje, como signo social y cultural, puede ser lugar de exclusión para los actores no favorecidos por las hegemonías culturales, que han tenido que ir construyendo para la historia formas de visibilidad y de inclusión. Para Clifford (1999), el concepto de viaje posee algunos prejuicios históricos que se encuentran asociados a unas "[...] prácticas europeas, literarias, masculinas, burguesas, científicas, heroicas, recreativas" (p. 48). Estas afirmaciones nos limitan la concepción de viaje hacia parámetros de marcado privilegio sociocultural, y el privilegio no puede ser obtenido bajo 
condiciones de desventaja de género, raza, credo o condición socioeconómica. Por tanto, las posibilidades de movilidad han sido limitadas o han estado sujetas a condiciones impuestas por "otros" sí autorizados para el viaje: "Pues en los relatos de viaje dominantes, una persona no blanca no puede figurar como explorador heroico, intérprete estético o autoridad científica" (Clifford, 1999, p. 49).

Frente a estos sectores sociales de poder, donde ha sido posible una mayor tendencia al viaje, surgen algunos interrogantes: ¿Quiénes son los que pueden y realizan viajes? ¿Qué papel han tenido las mujeres en el viaje?

Si partimos de la premisa de que el viaje es y ha sido expresión de desigualdades, encontraríamos muchos motivos para sostenerla; incluso actualmente podemos rastrear en nuestro continente el lugar que tienen los viajes en la vida de ciertos sectores sociales. En el pasado, fueron los europeos y las naciones imperiales como España, Francia e Inglaterra quienes se desplazaron buscando territorios que conquistar y colonizar.
Lo mismo ocurrió en el siglo XIX, cuando esas mismas colonias aportan los viajeros que llegarían a América, África y Asia. De igual manera sucedió en América, cuando los criollos viajaron a Europa buscando los rasgos de la modernidad en los centros de poder intelectual como Francia, Italia y España. También, algunas expresiones del viaje moderno, como el turismo, han sido propias de las clases privilegiadas. Augé (1998) nos hace un retrato de esto cuando afirma que, hoy día, los turistas de los países desarrollados viajan a los lugares de los que se quieren marchar los inmigrantes, ${ }^{1}$ como es el caso de mexicanos inmigrando a Estados Unidos y africanos inmigrando a las costas españolas.

En cuanto a la relación de la mujer y el viaje, muchos críticos han coincidido en que el género femenino se encuentra en la historia a un lado de la vida viajera. ${ }^{2}$ Asociada desde siempre al hogar, la mujer se encuentra relacionada a la vida fija, estable. El hombre, al parecer, es el que ha tenido la necesidad de realización a través del viaje, mientras la mujer solo puede encontrar su goce en la vida familiar.

Esta dicotomía cultural, a pesar de no ser tan clara hoy día, atravesó trechos grandes de la historia. La mujer ha tenido que verse inscrita y atada al hogar, en medio de las aventuras viajeras de los hombres. "El buen viaje (heroico, educativo, científico, aventurero, ennoblecedor) es algo que los hombres hacen (deberían hacer). Las mujeres se encuentran impedidas de realizar viajes serios. Algunas de ellas van a lugares distantes, pero en general como compañeras o excepciones." (Clifford, 1999, p. 46).

De esta manera, el viaje, y sus mitos de libertad e independencia, ha estado vinculado de manera directa a los hombres. Las mujeres han debido, en el mejor de los casos, restringirse a hacer un papel secundario en la vida viajera. Ni qué hablar de la escritura de viajes. Gracias a que las investigaciones sobre las mujeres que han escrito literatura de viajes se han ido extendiendo, conocemos que también existen esas "excepciones" de las que habla Clifford.

\footnotetext{
1 " [...] los países del Sur ven en el turismo una fuente de ingresos puesto que favorecen su desarrollo, aunque los beneficiarios directos del turismo en estas zonas suelen ser ciertas organizaciones e individuos de los países desarrollados. Desde este punto de vista, nuestra época se caracteriza por un contraste tan sorprendente como terrible, ya que los turistas suelen visitar los países de los que inmigrantes se ven obligados a irse, en condiciones difíciles y a veces, llegando a arriesgar su vida." (Augé, 1998, p. 62).

2 "La mujer solo viajaba por la fuerza, cogida como prisionera o esclava, y muy raramente por voluntad propia (haciendo referencia a la época de la antigüedad y el medioevo), Las viajeras literarias ingresan a la literatura de viajes a mediados del siglo XIX y de modo generalizado a comienzos del siglo XX (recordemos a la trágica Isabelle Eberhart, a la célebre Alexandra David-Neel, o poco más tarde a Ella Maillart)." (Gasquet, 2006, p. 62).
} 
La mayoría de ellas fueron mujeres europeas, pertenecientes a la clase burguesa, como lo fue la británica Anna María Falconbridge, una de las primeras en escribir un libro de viajes sobre África: Narrative of two voyages to the River Sierra Leone en 1802. También están las denominadas por Mary Louise Pratt como "exploradoras sociales": Mujeres reivindicadoras de causas sociales que llegan a América del Sur en el periodo posterior a la independencia, entre 1820 y 1840 , y escriben relatos de viaje. Entre ellas, encontramos el caso de Flora Tristán en Perú (Peregrinaciones de una paria) y María Graham Callcott en Chile (Journal of a Residence in Chile during the year).

A partir del siglo $\mathrm{XX}$, con el despliegue de las luchas femeninas que buscan instaurar el valor social de la mujer, las prácticas viajeras y la escritura de viajes creadas por mujeres se vuelven cada vez más numerosas. Sin embargo, el tema de la mujer y el viaje merece todavía una mayor atención, sobre todo en el análisis de esas formas de viaje propias de lo femenino que, según Clifford, no son tomadas como viajes importantes y válidos de ser estudiados. ${ }^{3}$

En esta confluencia de relatos de viajeros, y desplazamien- tos, se estampan los sellos de la historia y la cultura de los hombres; ningún país o aldea escapa a su influencia, ya que el viaje ha estado presente de forma constante. Por esto, la propuesta de Clifford de estudiar la cultura, no solo desde los asentamientos fijos y tradicionales de lugares establecidos, sino de también construir una propuesta de cultura a través de la dinámica del movimiento, se hace relevante. Tanto la vida sedentaria como los viajes posibilitan descubrir las coyunturas culturales de los pueblos, sus relaciones más o menos cercanas con el desplazamiento y el intercambio de costumbres, ideas, tradiciones, mitos y todas estas manifestaciones en continua transformación. "La cultura se estableció en base al localismo y a lugares cerrados [...] Se concebía la residencia de un lugar como la base local de la vida colectiva, mientras que el viaje era suplemento; las raíces siempre precedían a las rutas." (Clifford, 1999, p. 141).

El viaje, y sus diversas coyunturas sociales, donde viajeros y locales se entrecruzan en un movimiento interactivo y constructivo, resulta necesario integrarlo como un ente posibilitador de significados a la hora de pensar y estudiar nuestro continente, donde muchos de los procesos sociales e históricos se han debatido entre desplazamientos internos y migraciones. Ha sido a través del viaje que se han establecido muchos de los motivos de nuestras narrativas, en un intento de describir realidades tan complejas como abusadas, donde la estabilidad ha sido escasa y el movimiento sigue imperando como un denominador común de la vida latinoamericana. Incluso hoy día, en que todo parece descubierto y expuesto a una globalización arrasadora que no parece requerir el movimiento, este continente continúa debatiéndose entre todas las formas forzadas del viaje, donde miles de personas buscan una puerta hacia la estabilidad económica, y el continúo asecho de los gobiernos americanos y europeos por impedir la llegada de más inmigrantes a sus países.

Una mirada al género de la literatura de viajes

Al aproximarnos al género de la literatura de viajes, debemos tener en cuenta algunos problemas o dificultades de orden teórico, que, en vez de cerrar el horizonte de investigación, lo amplían y se convierten en posibilidades interesantes a la hora de acercarnos a este campo del estudio literario. Entre estos problemas teóricos, encontra-

\footnotetext{
3 “¿Y qué formas de desplazamiento, íntimamente asociadas con la vida de las mujeres, no son tomadas en cuenta como "viajes" valederos? ¿Las visitas? ¿El peregrinaje? Necesitamos conocer mucho más sobre cómo han viajado y viajan en la actualidad las mujeres, en las diferentes tradiciones e historias". (Clifford, 1999, p. 47).
} 
mos principalmente: la definición y las características propias del género, las tipologías como herramienta teórica y la metodología de análisis. También se podrían incluir como problemas teóricos: la cuestión del corpus siempre en constante cambio, la interdisciplinariedad del género, ficción y realidad, y el asunto de lo literario, entre otros.

El crítico Julio Peñate (2004) plantea que existen aspectos que complejizan la opción de una definición real de género de la literatura de viaje (aunque se intente hacer como una formalidad en los diccionarios especializados). Entre dichos obstáculos se pueden identificar: un corpus de obras variadas y de formas heterogéneas y libres, donde se vuelve difícil construir tópicos comunes; la condición interdisciplinaria, ya que el relato de viajes puede llegar a apropiarse de diferentes géneros y discursos, respetando a su vez las características propias de los mismos; el relato de viajes se puede nutrir de elementos de la autobiografía, epistolares, etnográficos, históricos, entre otros. Un ejemplo claro de esta situación puede ser el libro de viajes Sendas de Okú, de Matsúo Bashó, poeta japonés del siglo
XVII, donde se pueden encontrar dos géneros incorporados al relato de viajes: el haibun o prosa y el haikú o poema breve. Ambas expresiones literarias se encuentran expuestas sin mezclarse, conservando cada una su naturaleza e intencionalidad en el relato. En cuanto a este tema, restaría preguntarnos si sería mejor hablar de "definiciones del género" y no de una sola y única definición. Las definiciones se podrían exponer o estarían sujetas a los diferentes intereses u objetivos de los campos de estudio, lo mismo que al corpus de obras que se elija para dicho estudio. De esta manera, se podrían ampliar el modo y la forma de definir un género tan complejo y extenso como lo es el de la literatura de viajes.

Al lado de la definición, otro problema teórico del género, según Julio Peñate, sería el de las tipologías. Para la organización de un corpus tan extenso y variado, los críticos del género han tenido que valerse de esta herramienta. Existen innumerables tipologías, realizadas con diversos criterios y de acuerdo con las finalidades de las investigaciones críticas; como herramienta son útiles, ya que posibilitan establecer un orden a la hora de abordar las obras. Sin embargo, según Peñate, son un campo limitado debido a diversos aspectos, por ejemplo, que "se fundan casi exclusivamente en la anécdota narrativa", priorizando el argumento de la historia. Es el caso de los denominados viajes de peregrinos, viajes de exploración y aventura, viajes de viajeros imaginarios, etc. Otro problema importante de las tipologías, según el autor, es que tienen en cuenta solo al viajero: "suponiendo que sólo él puede dar cuenta de la anécdota narrativa y del conjunto del texto" (p. 23). Ejemplo de esto son el viajero pensador, el flâneur, el turista, entre otros. Este asunto es muy importante, ya que vendría a perfilar un punto reincidente del análisis de los relatos de viaje y es el "punto de vista del viajero"4. Este enfoque de las tipologías se ha centrado en la "motivación u objetivos del viajero en su etapa inicial", obviando las posibilidades de cambio que se pueden generar en el viajero a través de la travesía. Las tipologías pueden dar, de manera superficial, la garantía de un orden; pero, finalmente, no logran responder en su totalidad la complejidad de un género como el de la literatura de viajes, tan diverso y amplio en formas de escritura.

\footnotetext{
$4 \quad$ La mayoría de las veces se ha querido abordar las obras de viajes desde el sujeto viajero, dejando de lado otros aspectos también relevantes, como el punto de vista de los "otros o visitados". Mary Louise Pratt ha sido de las primeras críticas en intentar abordar otros aspectos textuales, intentando eliminar lo que ella describe como "mimesis crítica", producto de una extrema identificación con el autor y el protagonista viajero; dicha crítica se vuelve cegata ante el sentido de alteridad y el aporte intrínseco de los que acogen y reciben al viajero, y que pueden ser significativos en el proceso de análisis de las obras de viajes.
} 
Otro aspecto teórico del género, muy importante y bastante complejo, ya que abarca diversos puntos de vista críticos, haciendo difícil obtener una conclusión única, es el tema de la metodología de análisis del género de la literatura de viajes; tema largamente discutido $\mathrm{y}$ que no ha dejado de ser un reto más para el estudioso del género. Las preguntas que bien valdrían hacernos serían: ¿Cómo analizar relatos de viaje? ¿Existe un método de análisis?

De manera general, se ha querido priorizar en el análisis de los textos de viajes aspectos como: el área temática -que ha sido la de mayor análisis-, donde se abordan grandes tópicos como el de la ciudad, el exotismo y los medios de transporte, entre otros. De la forma estructural de las obras, se han estudiado el tiempo y el espacio, la manera de desenvolverse la trama y los recursos dramáticos; y en cuanto al contenido propiamente, se han estudiado aspectos como la transformación del viajero, las funciones del azar y los grandes acontecimientos en el desarrollo de la narración, las descripciones como fuente de información, etc. Faltaría en esta enumeración añadir otros recursos de análisis que se han ignorado, como el plano expresivo, el plano estructural y lingüístico, la relación del relato de viaje con su contexto histórico. Sin embargo, actualmente se han incluido nuevas fronteras críticas al género, sobre todo a partir de los estudios poscoloniales, donde se tienen en cuenta aspectos históricos y socioculturales, a la hora de abordar este tipo de literatura.

Sofía Carrizo Rueda es otra estudiosa del género que ha propuesto una forma más de abordar las obras de viajes. La crítica empieza por diferenciar la literatura de viajes del relato de viajes. La diferencia entre estas dos formas de escritura -si bien este tema sigue en debate crítico- sería que, según la autora, la literatura estaría más vinculada con elementos ficcionales y el relato tendería más a lo documental e informativo. Sin negar el carácter inclasificable y complejo de muchas obras que huyen de estos estereotipos, Carrizo parte de esta diferenciación para elaborar una propuesta crítica de las obras, donde elementos como la descripción y el desenlace están cumpliendo funciones diferentes tanto en la literatura de viajes como en el relato de viaje, ya que, por ejemplo, dentro del relato de viajes se encuentra casi difuminada la expectativa por el final de la trama, no ocurre así en la literatura de viajes, donde sí hay clara motivación por la espera del desenlace. Tendríamos entonces una señal clara de que el relato de viajes se sumerge más en funciones descriptivas, mientras la literatura sigue priorizando el contexto dramático de la historia.
En los relatos de viaje, resulta fundamental observar detenidamente qué aspectos recoge cada descripción. Y, asimismo, qué aspectos calla. Para los historiadores será un modo de acercarse a su mayor o menor veracidad $\mathrm{y}$, para quienes deseen efectuar un análisis literario, el medio de poder dilucidar qué imagen de mundo es la que finalmente proporciona el texto. (Carrizo, 1999, p. 350).

De igual forma, esta diferenciación discursiva no tiene que cumplirse a cabalidad en todas las obras, tampoco en todas las obras podemos establecer con claridad incuestionable estas actitudes. Por otro lado, Carrizo propone otro componente metodológico: la cuestión del emisor-receptor del texto, donde se vinculan las pretensiones del autor en el horizonte de recepción del relato; implica todo lo que el emisor o autor desea proponer en su obra y que se convierte en otro elemento de análisis importante a la hora de rastrear las huellas que marca el relato de viajes en su momento histórico y en sus posibles lectores, que también están enmarcados en una situación social y cultural específicas. Este aspecto metodológico lo podemos ligar con la repercusión o la búsqueda de significados históricos y sociales que se pueden hallar en las obras de viaje. Finalmen- 
te, el género está vinculado con diversas formas de representación cultural, lo que supone su conexión con las creencias e ideologías de las sociedades por las que se viaja.

Lo mismo sucede con los presupuestos teóricos sobre la escritura de viaje, como lo sugería anteriormente; en la actualidad, la mirada de análisis de las narrativas de viajes está más cercana a metodologías interdisciplinarias donde pueden confluir la etnografía, la geografía y la crítica literaria, bajo el amparo de las teorías poscoloniales y los estudios culturales. En esta nueva perspectiva se tienen en cuenta aspectos como las formas autobiográficas, tópicos de la otredad y representación cultural, entre otros. Desde este enfoque, se pretende establecer nuevas propuestas para interpretar las dinámicas del viaje y las voces que en él hablan, donde identidades y subjetividades se transforman de manera constante. Para la crítica feminista Linda McDowell (2000), uno de los grandes logros de los estudios teóricos actuales en el campo de la narrativa de viajes es el concepto de "diferencia", ya que "desempeñó un papel fundamental contra el falocentrismo y universalismo del discurso occidental" (p. 315).

Del relato de viajes a la literatura de viajes, todas las categorías que se le imponen al género parecieran insuficientes y limitadas. ¿Cuántos relatos no son atravesados por la ficción y cuántas novelas de viajes no son testimonio de realidades históricas? Para intentar no encasillar o sobrevalorar algún aspecto del género, haciendo divisiones que promuevan un juicio de valor y conociendo de antemano lo problemático que resulta hablar de "literatura", la crítica y periodista Pilar Rubio (2006) prefirió el término "narrativa de viajes" como una propuesta para totalizar las "formas del relato escrito", diferenciando dichas narrativas de viajes que estarían más sujetas a los viajes reales donde confluyen lo testimonial y lo literario, de la novela de viajes "encuadrada necesariamente en un armazón ficcional" (p. 248). Estas dos grandes categorías constituirían el género de viajes.

Relato, literatura, narrativa, son nominalismos usados en un intento por delimitar las características de un género, que, si bien hace parte de la constitución primigenia de la literatura clásica, también ha ido diversificándose en variadas y novedosas formas, donde el viaje ha encontrado su lugar para ser testimoniado. De igual manera, son variados los criterios que los críticos han asumido para abordar y sacar el mejor provecho de los textos de viajes. Dichas "narrativas de viaje", hoy día, integran nuevos retos para los escritores y los críticos, gracias al auge creciente de las for- mas de representación como la fotografía y el video, cambiando el tipo de relación con esa otredad perceptible en el viaje y que está siempre susceptible de ser descrita. La escritura de viajes ha transformado sus fronteras, se ha ido adaptando a las nuevas perspectivas $\mathrm{y}$ formas de comunicación: Guías y blogs de viajes se toman el espacio para testimoniar la experiencia del desplazamiento. De igual forma, se continúan actualizando las formas tradicionales como la novela, la crónica y los diarios de viaje, lo que hace que el material de estudio siga vigente $\mathrm{y}$ en continuo crecimiento, e incluso rehaciendo la forma de percibir y entender lo literario, que no necesariamente debe adaptarse a los límites del canon.

Breve recorrido histórico del género de la literatura de viajes en Latinoamérica

Las raíces de la literatura de viajes en Latinoamérica están, sin duda, en ese momento crucial para la historia cultural del mundo, como fue la llegada de los europeos a las tierras americanas. Misioneros y conquistadores fueron los primeros viajeros que tuvieron la oportunidad de enfrentarse a los pueblos americanos. Son esos primeros viajeros los que describirán en sus libros de viaje las primeras crónicas de las Indias, que más tarde serán valoradas por los críticos como escritos etnográ- 
ficos. Dichas crónicas de indias serán la fuente para rastrear los testimonios que evidenciarían las relaciones del europeo frente al indígena. En su libro $E l$ Viajero y la Memoria, el crítico literario Fabio Martínez (2005) se pregunta sobre ese momento histórico: “¿Cómo se produce este primer encuentro con un mundo hasta ahora desconocido? ¿Cómo se efectúa ese proceso de alteridad y de reconocimiento del otro?" (p. 32).

La respuesta que nos da el autor resulta acertada y oportuna, ya que si bien Cristóbal Colón propicia en Europa el deseo del viaje, haciendo posible el reconocimiento de un mundo más amplio y extenso, la misión conquistadora implanta una interacción cultural que no está de ningún modo presente dentro de los cánones de reconocimiento de las diferencias, sino va a predominar la negación del otro; la condición de indígena es vista por el europeo como inferior, propiciando el éxito del proyecto de la conquista y la colonia en el continente americano. "[...] Cuando Colón y los misioneros nombran y descubren al indio, lo hacen desde su lengua, desde su cultura, desde su religión, borrando cualquier posibilidad de reconocimiento del otro, evitando cualquier alterna- tiva de intercambio dialógico." (Martínez, 2005, p. 34).

Por esto, en los siglos XVI y XVII predominarían imaginarios y representaciones contaminados por una visión sesgada y parcial, donde los misioneros y conquistadores intentarán abolir las diferencias culturales a través de imposiciones religiosas e ideológicas propias de su cultura. Cabría entonces preguntarnos si esta situación se acaba en los siglos siguientes o si, mas bien, se disfraza con otros mecanismos de dominación más sutiles y en apariencia inocentes; como se puede dilucidar en el proyecto científico del siglo XVIII, donde el misionero y conquistador le dieron paso al científico naturalista.

Para la segunda mitad del siglo XVIII, se inicia un nuevo proyecto de viaje, direccionado al mundo del conocimiento y la ciencia, como lo sería la recopilación de la historia natural del mundo. Este proyecto se realizaría de forma paralela y similar en América, Asia y África; grandes expediciones como $\mathrm{La}$ Condamine, representarían los inicios de este proyecto europeo que marcaría, como dice Mary Louise Pratt (1997): “[...] un cambio en la concepción de Europa de sí misma y de sus relaciones globales." (p. 52). En estos viajes, Europa se mantendría al margen de propósitos de explotación, para recuperar un nuevo tipo de viajero, que ahora coleccionaba y clasificaba plantas y animales alrededor del mundo, mientras respetaba la naturaleza. ${ }^{5}$ ¿Qué había detrás de este proyecto de clasificación del mundo natural? ¿Qué consecuencias tuvo en la historia global de occidente? Para la crítica literaria Mary Louise Pratt (1997), este proyecto de sistematización de la naturaleza no era tan benigno como se pretendió mostrar al mundo, sino, por el contrario, establecería aún más el abismo entre el llamado mundo civilizado racional del europeo y el denominado mundo salvaje e inculto de las colonias: "Es posible encontrar aquí una imagen utópica de un sujeto burgués europeo, simultáneamente inocente e imperial, imponiendo una visión hegemónica inofensiva, que no instala aparato alguno de dominación." (p. 71).

La dominación a través del conocimiento se vuelve posible al constatar que la relación entre el que ve y los que son observados es desigual, lo que ocasiona que la sistematización racional del mundo natural esté cargada de discursos de élite, impuestos sobre pueblos subvalorados. ${ }^{6} \mathrm{El}$ europeo continúa expandiendo

5 "Comparado con el navegante o el conquistador, el naturalista recolector es una figura benigna u con frecuencia hogareña, cuyos poderes transformadores actúan en los contextos domésticos del jardín o de la sala de colecciones” (Pratt, 1997, p. 55). 
su visión imperial, pero ahora de manera menos evidente. Para Mary Louise Pratt, las consecuencias futuras de este proyecto naturalista reflejarían, ya sin velos, como la sistematización de la naturaleza englobaría al mundo en un esquema controlado, donde incluso los hombres estarían incluidos.

El científico naturalista se encuentra por fuera de su propuesta sistemática del mundo, él es quien impone orden y nombra, instalándolo en un lugar privilegiado, casi en la escala de creador. Más adelante, este proyecto sería el inicio de lo que se convertiría en la estructura de la "vida burguesa"7, donde la figura del Estado sería organizada desde patrones socioeconómicos que ejercerán el control, imponiendo modelos de vida y excluyendo otras formas de organización social y cultural, consideradas como no válidas a la hora de competir con estos "modelos" hechos a la medida de la razón civilizadora.

Con la llegada del siglo XIX, se inaugura el que ha sido denominado "el gran siglo viajero"; el mundo necesitaba ser redescubierto y descrito, y muchos europeos se desplazaron por el mundo con el ánimo de mirar por sí mismos tierras lejanas y extrañas. Al continente americano llegaron ingleses, suecos y alemanes, entre otros. La mayoría de ellos escribieron diarios de viaje, durante el viaje o cuando volvían a sus países de origen. Estos eran el material de la época a través del cual era posible saber sobre el mundo. Después de tres siglos de colonialismo español, las nacientes naciones americanas se convirtieron en un potencial mercado de materias primas para explotar, lo mismo que un territorio inexplorado y exótico para muchos viajeros. Algunos de ellos llegaban a América con misiones diplomáticas o mercantiles; otros llegaban por pedido de los propios gobiernos americanos para que trajeran sus ideas de progreso y sus conocimientos en campos como la educación, la geografía, la economía y las aplicaciones prácticas como la ingeniería. ${ }^{8}$

A partir de la independencia, las ideologías europeas fueron parte del pensamiento americano. Europa fue un punto de referencia importante para la conformación de las nuevas naciones, ya que era hito de los valores del progreso, por lo cual desde el siglo XIX hasta las primeras dos décadas del siglo $\mathrm{XX}$, muchos criollos hispanoamericanos también viajarían a Europa buscando una realidad que les hablara de la modernidad y la civilización de la que carecían las nacientes naciones americanas. Dicho viaje se establece en la pequeña burguesía criolla como una forma de estatus social y aprehensión cultural. Para los criollos, era

$6 \quad$ Tal vez sea oportuno recordar que esto sigue ocurriendo en algunos sectores académicos en la actualidad, y que ha ocurrido desde prácticamente el comienzo del siglo XX, con el advenimiento de la nueva antropología social fundada por Malinowski, tanto en América como en todo el tercer mundo. Este asunto puede resultar más complejo, ya que ese poder de clasificar y denominar desde una perspectiva hegemónica, no es exclusivo de los europeos, sino de la élite académica, sin importar su nacionalidad.

7 "La sistematización de la naturaleza lleva esta imagen de acumulación a un extremo totalizado, y al mismo tiempo modela el carácter extractivo, transformador del capitalismo industrial, y los mecanismos ordenadores que empezaron a dar forma a la sociedad de masas urbana en Europa bajo la hegemonía burguesa. Como constructo ideológico, la sistematización de la naturaleza representa al planeta apropiado y reorganizado desde la perspectiva unificada, europea". (Pratt, 1997, p. 73).

8 Entre los extranjeros más prominentes de este periodo, encontramos nombres como: Charles Stuart Cochrane, inglés que emprendió un recorrido en barco por América, pasó por Venezuela, Colombia, entre otras regiones, y se involucró en el comercio de perlas. Dejó consignadas sus aventuras en el Journal of a residence and travels in Colombia, during the years of 1823 and 1824. Edouard Francois André, arquitecto y paisajista francés, realizó un viaje entre Barranquilla y Quito en 1870 , recopilando información sobre plantas ornamentales. Fue auspiciado por su gobierno y dejó registrada su travesía en crónicas publicadas en la revista francesa Le Tour du Monde. Otro francés, Gabriel Lafond de Lurcy, marino, recorrió la costa pacífica de Hispanoamérica. Dejó escritos varios documentos sobre economía, la educación y el clima de sus viajes por el continente. William Eleroy Curtis, viajero diplomático y periodista, en 1880 viajó a América Latina, enviado por su gobierno para evaluar el potencial comercial de la región. 
parte del viaje tratar de leer y descifrar lo europeo, y luego escribirlo en sus narraciones de viaje. Muchos de estos viajeros ya conocían y habían leído libros de viaje a través de todo el auge libresco que el género de viajes había producido en Europa. Cada viajero escribe su versión de París, España, Italia; entre estos escritores tenemos a Rubén Darío, Enrique Gómez Carrillo, José Enrique Rodó, Aurelia Castillo y Juan José Tablada, entre otros. En Colombia, una obra que ejemplifica este periodo es De sobremesa, de José Asunción Silva, escrita en 1896 y publicada en 1925; la obra narra el viaje del poeta y hombre de negocios José Fernández a Europa, quien escribe un diario donde se puede leer las crecientes diferencias entre la vida provinciana de Santa Fé de Bogotá y el mundo cosmopolita europeo.

También en este periodo, muchos escritores viajeros hispanoamericanos quisieron afianzar la importancia de recorrer sus propias geografías, en muchos casos como una manera de recuperar o consolidar la esencia americana, cuando el auge de la modernidad en el mundo y de las potencias extranjeras se filtraba en el continente. Ejemplo de ello, en la Colombia del siglo XIX, fueron Max Gillo, Miguel Triana, José María Samper, Soledad A. Samper, Medardo Rivas y Emiliano Restrepo, entre muchos otros. En el siglo XX, se encuentran figuras como Germán Arciniegas, Eduardo Caballero Calderón y José Eustasio Rivera, Fernando González Ochoa, Eduardo Zalamea Borda, dos escritores viajeros colombianos que recorrieron regiones del país, como el Eje Cafetero, el Pacífico y la Guajira.

Después de recorrer los diferentes momentos de la historia del género de la literatura de viajes y exponer cómo a partir de la llegada de los españoles, se genera para el continente americano un silencio e invisibilidad de sus formas de vida, siendo opacadas y subvalorizadas por las potencias coloniales, nos preguntamos cuál será la situación del siglo XX frente al género de la literatura de viajes en América Latina, y más propiamente en Colombia.

La crítica literaria Elena Palmero, en su artículo sobre el escritor Alejo Carpentier, hace un recorrido sobre la evolución del discurso de viaje en la narrativa ficcional de Latinoamérica. Palmero visualiza tres momentos importantes donde el viaje, como motivo narrativo, se toma la ficción para hacer parte imprescindible de los procesos literarios del continente. Un primer momento se da en las primeras etapas del siglo XX; la crítica identifica una narrativa sujeta a un modelo "decimonónico" y "convencional", donde priman la historia por encima de la voz del viajero: "Textos de temporalidad dilatada, de evidente distancia entre los tiempos del contar y los tiempos de la historia contada, y en las que el afán del escritor se concentra en la acumulación de información en detrimento de la imagen del informante o de cualquier mecanismo que exteriorizara las relaciones pragmáticas del relato". (Palmero, 2006, p. 30).

En este periodo estaría el componente del viaje inmerso en la anécdota y los sucesos, lo que lleva como consecuencia un modelo narrativo temporal, lineal y estructurado. Este periodo tiene como referentes las novelas Raucho de Ricardo Güiraldes, La vorágine de José Eustasio Rivera y Canaima de Rómulo Gallegos. Para mediados del siglo, Palmero identifica un cambio radical en dicho modelo, para cederle paso a una narrativa que juega a fracturar el tiempo, asimilando posturas más complejas frente a la forma de narrar las temporalidades, incluso buscando en el espacio mítico una vía para contrarrestar el predominio del tiempo cronológico. De igual modo, será recurrente en el discurso de viaje la apropiación de ideologías menos progresistas, aceptando visiones más ligadas al retorno del origen, como posibilidad de un rescate de la identidad. Entre las novelas que ejemplifican este modelo, la autora cita Los pasos perdidos de 
Alejo Carpentier y La casa verde de Vargas Llosa, entre otras.

Hacia finales de los años 80 y 90, Palmero denomina como "performance" el novedoso encuentro entre lo ficcional y lo escritural, donde se privilegia las formas de representación en la novela, llegando incluso a la parodia, como una forma de subvertir los discursos homogéneos, resueltos y claros a nivel formal. Entre las obras que la autora menciona están Vigilia del almirante de Augusto Roa Bastos y El arpa y la sombra de Alejo Carpentier. Finalmente, en los años noventa, las narrativas de viajes se conformarían a partir de lo migrante: personajes en permanente travesía, que hablan tanto desde fuera de sus lugares de origen como dentro de ellos. Las narrativas de cubanos y mexicanos expuestas desde los Estados Unidos, pueden ser un buen ejemplo de esto, afirma la autora.

Luego de este breve recorrido histórico, podemos concluir que la constante reiteración del viaje dentro de las narrativas de ficción puede estar vinculada a la búsqueda del espacio narrativo como un lugar para describir y representar las identidades latinoamericanas, lo que lleva a encontrar en la narrativa de viajes, en los viajeros y visitados, un perfil de ayuda a la consolidación de un testimonio que cuente lo americano, en esos espacios narrativos híbridos, descentrados, que asumen desiguales y extensas temporalidades para recrear, desde el viaje, la esencia cultural y diversa de un continente.

De igual manera, podemos afirmar que la narrativa de viajes en el continente ha tenido una gran importancia dentro de los procesos de construcción de la memoria y la identidad del continente, gracias a que se muestra como un lugar indicado para evidenciar geografías e imaginarios que nos hablen de nuestras transformaciones y de nuestros procesos de cambio a través del paso de los siglos. La permanencia del género de la literatura de viaje está vinculada a todos los asuntos y problemáticas sociales de violencia, desplazamiento y migración; fenómenos presentes en la vida de los latinoamericanos, y que seguramente serán ejes importantes para la permanencia y el desarrollo del género de la literatura de viaje no solo en Latinoamérica sino también Colombia.

Así, seguimos reconociendo en el género de la literatura de viaje un amplio espectro crítico que da cabida a variadas definiciones conceptuales y formas heterogéneas del relato escrito donde se puede incluir lo ficcional y lo referencial de las historias; además de permitir textualidades estéticas que no necesariamente están permeadas por un canon estrecho, sino que juegan con propuestas menos heterodoxas como los blogs, las guías de viaje, y por supuesto, las de orden audiovisual, como la fotografía y el cine, formas artísticas siempre susceptibles de ser interpretadas.

Por otro lado, su discurso siempre en constante cambio permite establecer y dilucidar cómo ha sido asimilado el imaginario cultural de los pueblos a través de la historia, imaginarios que muchas veces han sido construidos a través de representaciones estereotipadas que fijan y limitan la imagen de las culturas. Sin embargo, también el relato de viaje puede ser fuente para entender la conformación identitaria de grupos sociales y étnicos, lo mismo que puede ser un instrumento para descubrir la memoria de tantas voces opacadas por los discursos masculinos, coloniales y occidentales.

Para finalizar, nuestra tarea como críticos del género es exponer cuánto de peligro existe en caer en versiones universales y estereotipadas de los pueblos y culturas. El reto estaría en contribuir a profundizar y ampliar el espectro crítico de estas narrativas viajeras y cómo han ido incidiendo en los imaginarios que hoy tenemos de los Otros: llámense continentes, países o regiones. 


\section{Referencias}

Adichie, Ch. (2010). El peligro de una sola historia. Arcadia. Recuperado el 10 de octubre de 2010, de http://www.revistaarcadia.com/periodismo-cultural-revista-arcadia/ideas/articulo/el-peligro-sola-historia/22338.

Augé, M. (1998). El viaje imposible: el turismo y sus imágenes. Barcelona: Gedisa.

Biblioteca Virtual Luis Ángel Arango. (s.f.). Viajeros por Colombia. Recuperado el 4 de agosto de 2010, de http//www.lablaa.org/blaavirtual/historia/galeria/ autores.html.

Biblioteca Virtual Luis Ángel Arango. (1970). Viajeros extranjeros en Colombia: siglo XIX. Cali: Carvajal \& Cia.

Candelier, H. (1994). Riohacha y los indios guajiros. Biblioteca virtual Biblioteca Luis Ángel Arango. Recuperado el 10 de diciembre de 2010, de http://www.banrepcultural.org/blaavirtual/historia/ riohacha/rioindice.htm.

Carrizo Rueda, S. (1999). Analizar un relato de viaje. Una propuesta de abordaje desde las características del género y sus diferencias con la literatura de viajes. En: R. Beltrán, Maravillas, peregrinaciones y utopías: literatura de viajes en el mundo románico (pp. 343-352). España: Universitad de Valencia.

Corporación Fernando González (s.f.). Otraparte. Recuperado de www.otraparte.org.

Clifford, J. (1999). Itinerarios transculturales. Barcelona: Gedisa.

González, F. (1989). Viaje a pie. París: Le Livre Libre.

Hall, S. (1980). Codificar y decodificar. En: Cultura, media y lenguaje (S. Delfino, trad.). Londres: Hutchinson. Recuperado el 10 de noviembre de 2010, de http:/www.felsemiotica.org/site/wp-content/uploads/2014/10/Hall-Stuart-Codifi car-y-decodificar.pdf.

Martínez, F. (2005). El viajero y la memoria. Un ensayo sobre la literatura de viaje en Colombia. Cali: Universidad del Valle.

Mcdowell, L. (2000). Género, identidad y lugar. Un estudio de las geografias feministas. Madrid: Cátedra.

Múnera, A. (2005). Fronteras imaginadas. La construcción de las razas y de la geografía en el siglo XIX colombiano. Bogotá: Planeta.

Palmero, E. (2006). Poéticas del viaje en la narrativa de la alta modernidad: Los Pasos Perdidos de Alejo Carpentier. Revista de la Fundación Universidad Federal de Río Grande, 10(12), 23-34. 
Peñate, J. (2004). Camino del viaje hacia la literatura. En: J. Peñate. Relato de viaje y literaturas hispánicas (pp. 13-29). Madrid: Visor libros.

Pratt, M. L. (1997). Ojos imperiales. Literatura de viajes y transculturación. Buenos Aires: Universidad Nacional de Quilmes.

Rubio, P. (2006). Nuevas estrategias en la narrativa de viajes contemporánea. En: J. Pimentel. Diez estudios sobre literatura de viajes (pp. 243-255). Madrid: Instituto de la lengua española.

Said, E. (2004). Orientalismo. Barcelona: Debolsillo.

Todorov, T. (1991). Nosotros y los otros. Reflexiones sobre la diversidad humana. México: Siglo XXI.

Zalamea, E. (1960). Cuatro años a bordo de mí mismo. Diario de los cinco sentidos. Bogotá: Compañía grancolombiana de ediciones. 